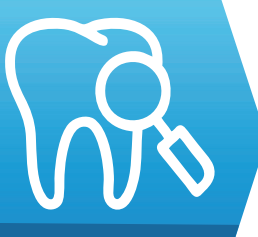

DENTAL MEDICINE

Orthodontics and Dentofacial Orthopedics Department, Government College of Dentistry, Indore, m.p., India

\section{Patterns and prevalence of canine anomalies in orthodontic patients}

Sandhya Jain, Sharmila Debbarma

\begin{abstract}
Objective. The aim of the present study was to present detailed information regarding the impacted maxillary and mandibular canines and their patterns of presentation into the oral cavity and to evaluate the prevalence of different canine anomalies, such as ectopic canine, transmigration, transposition and agenesis of permanent canines among central Indian population.
\end{abstract}

Method. A total of 1593 patients OPG's were thoroughly evaluated and the prevalence of different canine anomalies like impacted maxillary and mandibular canine, transmigration, transposition, agenesis and ectopic canine eruptions were evaluated. The canine angulation, vertical position in relation to occlusal surface of adjacent tooth's and the overlapping of adjacent teeth's crown by impacted canine was evaluated by tracings.

Result. Out of 1593 subjects, 22 patients had impacted canines. The prevalence of canine impaction was $1.38 \%$, with maxillary canine impaction of $0.93 \%$, mandibular canine impaction of $0.37 \%$, canine agenesis $0.06 \%$, transmigration $0.12 \%$, canine transposition $0.18 \%$ and the ectopic canine was $5.5 \%$.

Conclusion. There is no gender difference in canine impaction. The prevalence of canine impaction is $1.38 \%$.

Keywords: impacted canine, transmigration, transposition, ectopic canine, agenesis

\section{Introduction}

The different types of canine anomalies like ectopic canine eruption, canine transmigration, canine transposition, agenesis, impaction, usually occur due to the disturbances during development and eruption. Since the canines are the longest teeth in the oral cavity and the shape, position of the canines contribute to the guidance of the teeth into the intercuspal position, the canine teeth should be evaluated thoroughly in order to deliver the best treatment to the patients.

The impaction of tooth have been studied by many authors and various terminologies have been given in the literature to define impaction including delayed eruption, primary retention, submerged teeth, impacted teeth etc [1]. According to Abron et al, impaction can be defined as a deceleration of the normal eruption process of the tooth [1] and according to Lindauer et al, it can be defined as a impaction if it was not erupted after completion of the root development or if the eruption of the contralateral tooth was there for at least 6 months with completion of root formation [2].

The ectopic eruption is a condition where because of deficiency of growth in the jaw or segment of jaw, a primary tooth assumes a path of eruption that intercepts its premature loss and produces a consequent malposition of the permanent tooth [3]. Tooth transposition, is also a special type of ectopic eruption. It can be defined as a condition where the position of two teeth is interchanged or a condition where a tooth develops in the place of another tooth [4,5]. It can be divided into two types, complete and incomplete transposition. Complete transposition is when the crown and root surface of the teeth is completely transposed in different positions. In incomplete transposition, only the crown is displaced in another tooth position but the root remains in their normal positions [6].

The transmigration is a condition where a tooth crosses a midline. Previously, transmigration term was used where the whole impacted canine had migrated and

orthosharmila@gmail.com 
crossed the midline of the mandible [7]. But according to Javid, transmigration can be defined as a condition where one half or more of impacted canine crosses the midline $[8,9]$. According to various studies the prevalence of transmigration is suggested to be 0.1 to $0.34 \%$ in different populations [10-12].

Overall, the incidence of impacted maxillary canine is suggested to be $0.9-2.2 \%[13,14]$. But the incidence for mandibular canine impaction is at least 20 times lower than that of maxillary canine impaction [15]. However, the transmigration of canine, agenesis of canine and canine tooth transposition are even rarer anomalies.

The aim of our study was to present the detailed information regarding canine anomalies like impacted canines and their patterns of presentation in the oral cavity: ectopic canine, transmigration, transposition and agenesis.

\section{Material and method}

This is a prospective clinical study. The subjects for this study were selected from the patients attending the department of Orthodontics in the year of 2016. All the patients coming to the department of Orthodontics were thoroughly examined and checked for any missing permanent canine, retained primary canine and other canine anomalies. A total number of 1593 patients were evaluated for this study.

Patients were advised for OPG $\mathrm{x}$-ray for confirmation of the clinical examination. Different canine anomalies were determined from the Orthopantomogram. The method given by Lindauer et al was used to consider canine as impacted [2].

The tracings were made on acetate paper. The impacted canine, central incisor, lateral incisor on the impacted side were traced by lead pencil.

The impacted canines were evaluated for level, angulation and overlapping in relation to adjacent tooth. The angulation of the impacted canine was evaluated by tracing the long axis of the impacted canine in relation to mid-sagittal plane. The angulations were classified into mesioangular, vertical, distoangular and horizontal.

Since there were no exact criteria to classify according to the degree of angulations between the long axis of the impacted canine and the mid-sagittal plane, we performed a survey to decide the exact criteria; 10 senior resident orthodontists were asked to classify different angulations between mid-sagittal plane and long axis of impacted canine ranging from $5^{\circ}$ to more than $75^{\circ}$. After the survey the following angulation classification was used.

Mesioangular: when the long axis of the impacted canine was directed towards the mid sagittal plane and the angle is formed near the coronal area of the impacted canine with a range of angle between 15-70 degree. Distoangular: when the long axis of the impacted canine runs away from the mid-sagittal plane and forming the angle above the apical region of impacted canine. Vertical: when the long axis of the impacted canine is almost parallel with the mid-sagittal plane and the angle was between 0-15 degree. Horizontal: when the long axis of the impacted canine meets the mid sagittal plane at an angle more than 70 degrees (Figure 1).

The vertical position of the impacted canine in relation to the adjacent tooth can be classed as follows [16] (Figure 2,3);

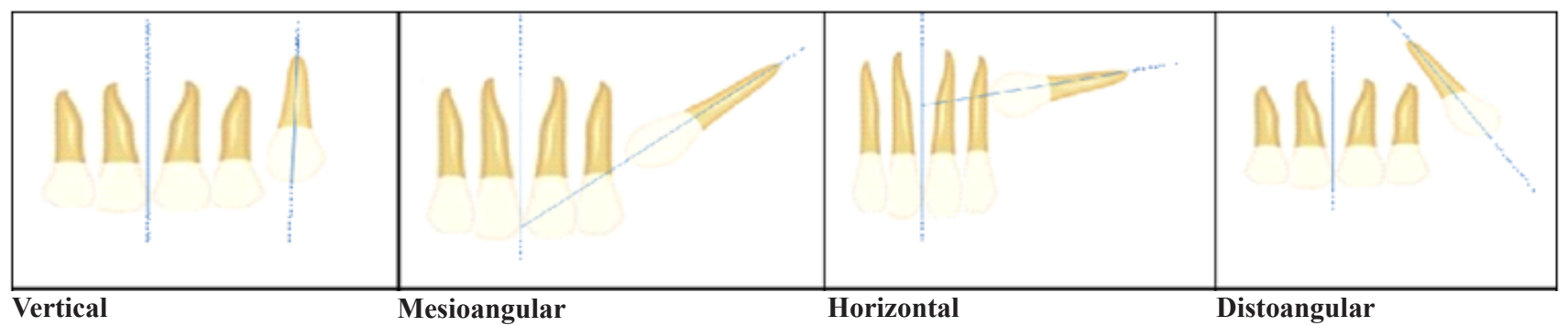

Figure 1. Showing the different angulations of impacted canine.

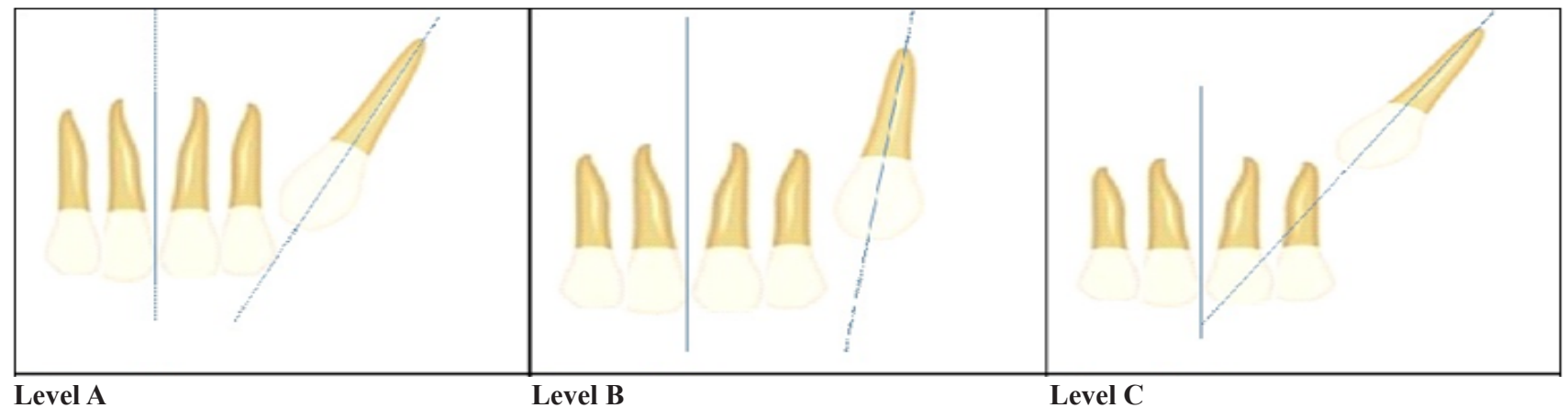

Figure 2. Showing the different depth of impacted canine (Levels). 


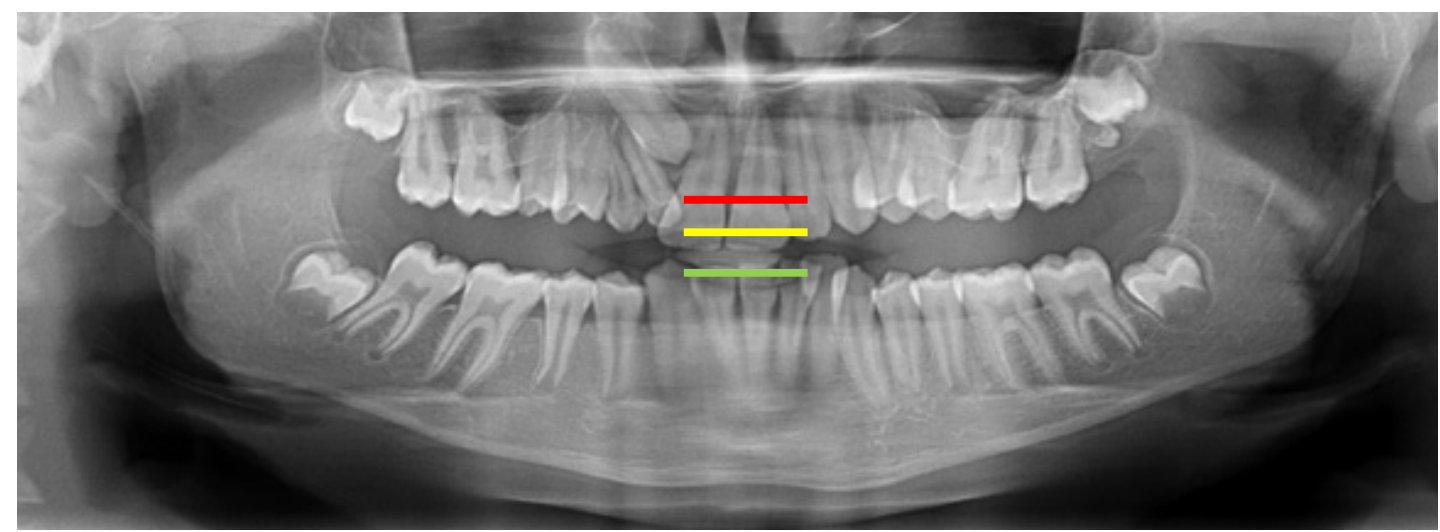

Figure 3. Showing the different levels, Level $\mathrm{A}=$ between green line to yellow line, Level $\mathrm{B}=$ between yellow line to red line, Level $\mathrm{C}=$ below the red line.

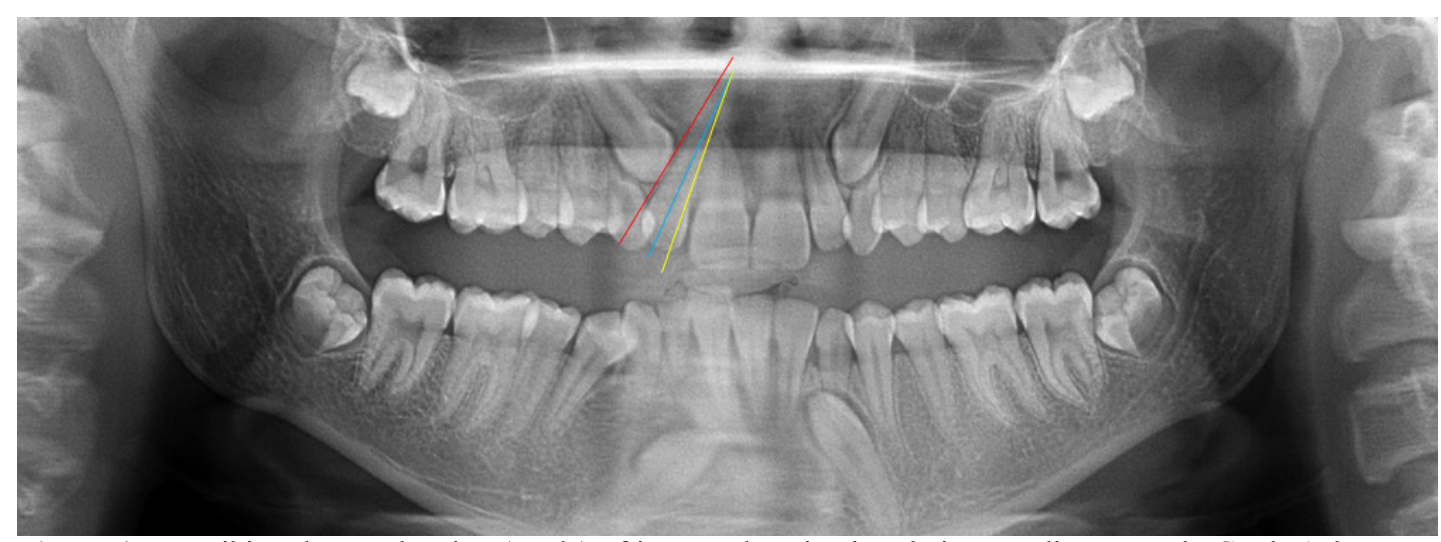

Figure 4. Describing the overlapping (grade) of impacted canine in relation to adjacent teeth. Grade 1: between the tip of the canine crown to red line; Grade 2: between the red line to blue line; Grade 3: between the blue line to yellow line; Grade 4: mesial to the yellow.

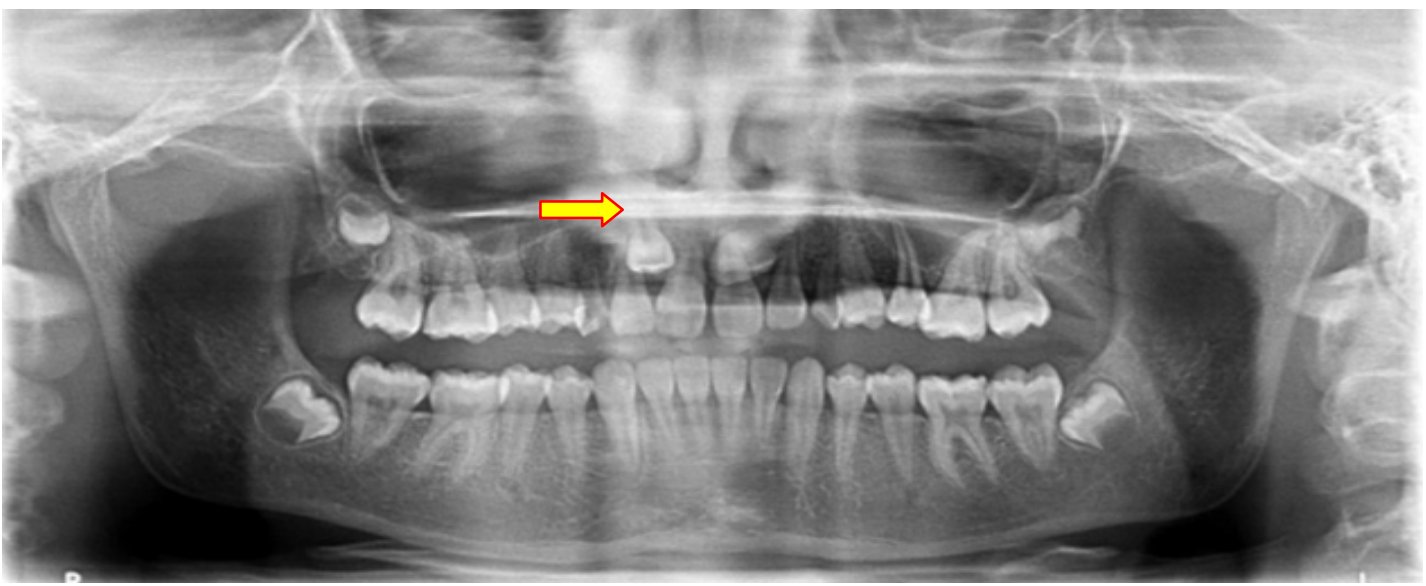

Figure 5. Complete transposition (maxillary right canine).

Level A, The impacted canine crown is touching the cervical line of the adjacent teeth. Level B, The impacted canine crown is positioned between the adjacent teeth cervical line and the adjacent teeth root apex. Level C, The impacted canines crown is positioned below the root apex of the adjacent teeth.

To determine the overlap of the adjacent incisor root by the impacted canine the following classification was used in this study [17,18]. Grade 1, no overlapping of the adjacent teeth; Grade 2, overlapping of adjacent roots less than half width; Grade 3, overlapping of greater than half root width, but not the whole root; Grade 4, overlapping of complete root width or greater than that (Figure 4).

For this study, complete transposition was considered when the crown and root surface of teeth was completely transposed in the different positions (Figure 5). 


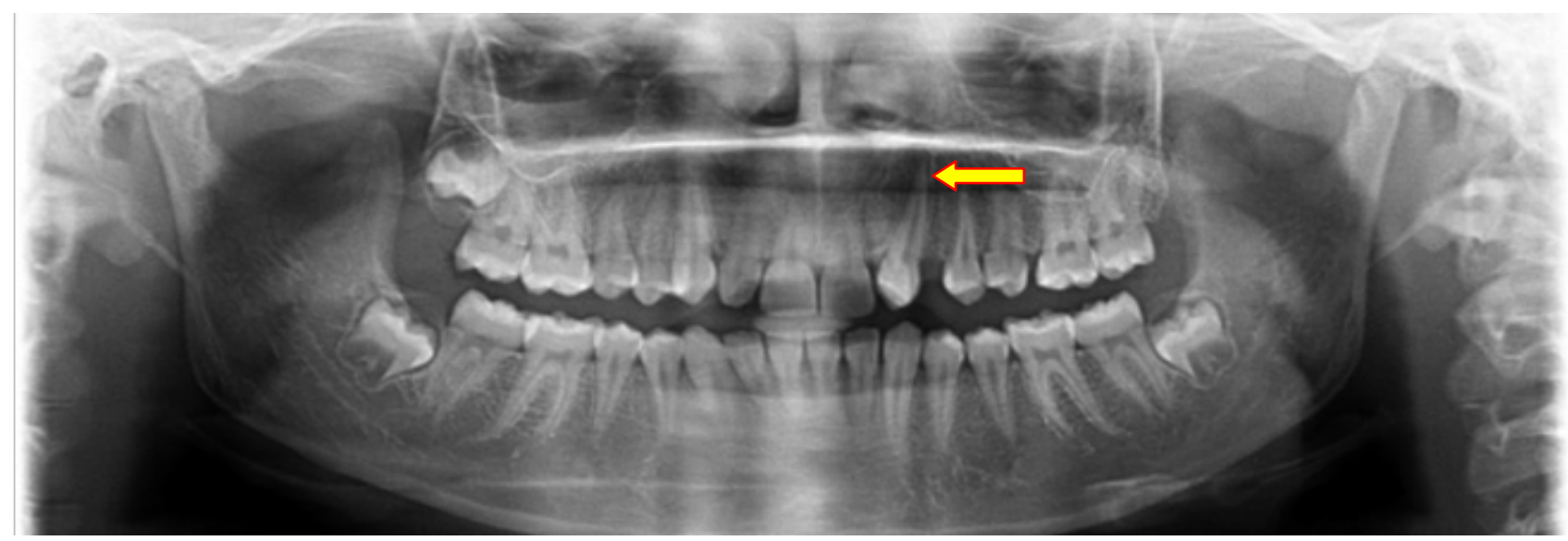

Figure 6. Incomplete transposition.

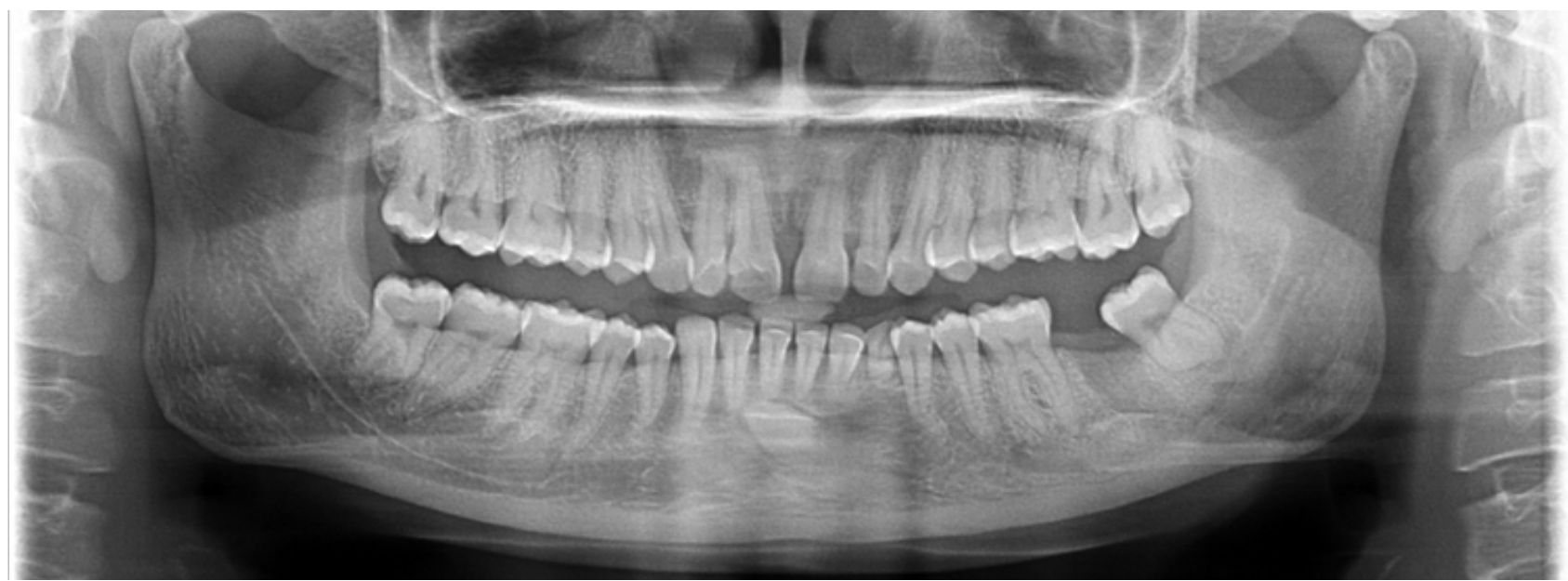

Figure 7. Transmigration.

Incomplete transposition, where only the crown was displaced in another teeth's position but the root remains in their normal positions (Figure 6).

Javid's definition for transmigration was used for this study according to which a canine was considered transmigrated when the one half of impacted canine or more than that of the impacted canine crosses the midline [7]. To further classify the transmigrant canines, the classification given by the Mupparapu was used [19]. The classification is as follows: Type 1, canine positioned mesioangularly across the midline, labial or lingual to the anterior teeth. Type 2, canine horizontally impacted near the inferior border of the mandible inferior to the apices of the incisor teeth. Type 3, canine erupting on the contra lateral side.

Type 4, canine horizontally impacted near the inferior border of the mandible below the apices of posterior teeth. Type 5, canine positioned vertically in the midline with the long axis of the tooth crossing the midline (Figure 7).

\section{Results}

Out of 1593 subjects, 22 (twenty-two) patients had at least one impacted maxillary or mandibular canine. Among the twenty-two subjects the total number of impacted canine teeth found was 36 and one missing permanent canine. The distribution of different patterns of 36 canine anomalies were as follows: transmigration, 2 teeth and only in the mandibular arch; canine transposition, 3 teeth (1 complete, 2 incomplete), 31 impacted canine (25 in the maxillary arch and 6 in the mandibular arch). The present study, the prevalence of overall (both maxillary and mandibular) canine impaction found was $1.38 \%$, only maxillary canine impaction was $0.93 \%$ and mandibular canine impaction $0.37 \%$, canine agenesis $0.06 \%$, canine transmigration $0.12 \%$ and only in the mandibular arch, canine transposition was $0.18 \%$ and only unilateral. The ectopic canine was found in $5.5 \%$ of patients. More than $95 \%$ of ectopic canines were present in the maxillary arch. Almost all the patients in this study were not aware of the condition but only two patients had complained of bulging of the soft tissues, as the tooth was erupting in the upper buccal mucosa.

In this study we have also observed the prevalence of total number of canine impaction per subjects. Out of 22 subjects, only 1 (unilateral) impacted canine was the most prevalent, which was observed in $14(63 \%)$ subjects, the 
second most common was the 2 (bilateral) impacted canine per subjects, present in $4(18 \%)$ patients. Equal distribution was observed, where $2(0.9 \%)$ patients had all 3 impacted canines and $2(0.9 \%)$ patients had all 4 impacted canines.

Table I depicts the patterns of impacted canines, which include the angulation, level of impaction and grade (overlapping of adjacent teeth). In the angulation category the mesioangular angulation was the most common finding, followed by vertical, then horizontal. In this study none of the impacted canine showed distoangular angulation. In the presentation of vertical heights (Level) of impacted canine, the level B was the most prevalent and level $\mathrm{A}$ and level $\mathrm{C}$ shows almost equal frequency.
Grade 1 and grade 2 again showed almost equal incidence and most prevalent in the grade's category, followed by grade 4 , while grade 3 was the least finding.

Table II shows the occurrence of impacted canine according to gender.

Table III presents t prevalence of impacted maxillary canine observed in different populations.

Table IV shows the prevalence of impacted mandibular canine observed in different populations.

Table V shows the prevalence of transmigration in different studies.

Table I. Patterns of impacted canine presentation.

\begin{tabular}{lll}
\hline ANGULATION & LEVEL & GRADE \\
\hline Mesioangular $=25(71 \%)$ & Level A=5 $(14 \%)$ & Grade 1=11 $(31 \%)$ \\
Distoangular $=0$ & Level B=26 $(74 \%)$ & Grade 2=12 $(34 \%)$ \\
Vertical $=8(22 \%)$ & Level C=4 $(11 \%)$ & Grade 3=3 $(8 \%)$ \\
Horizontal $=2(5 \%)$ & & Grade 4=9 $(25 \%)$
\end{tabular}

Table III. Prevalence of impacted canines according to gender.

\begin{tabular}{l|ll|l} 
Impacted canine & Female & Male & \\
Total 19 subjects & $9(47 \%)$ & $10(52 \%)$ & $(\mathrm{p} \geq 0.823)$
\end{tabular}

Table III. The prevalence of impacted maxillary canine observed in different populations.

\begin{tabular}{lccc} 
Study & Population & Year & Incidence \\
\hline Arandi et al [20] & Palestinian Population & 2017 & $1.8 \%$ \\
Sajnani AK, King NM [21] & Southern Chinese & 2014 & $2.1 \%$ \\
Aydin et al [22] & --- & 2014 & $3.29 \%$ \\
Saglam AA, Tuzum MS [23] & Turkish population & 2003 & $2.9 \%$ \\
Present study & Central Indian & 2017 & $.93 \%$
\end{tabular}

Table IV. The prevalence of impacted mandibular canine observed in different population.

$\begin{array}{lccc}\text { Study } & \text { Population } & \text { Year } & \text { Incidence } \\ \text { Aydin et al [22] } & ---- & 2014 & 0.44 \% \\ \text { Yavuz MS et al [16] } & \text { Turkish subpopulation. } & 2007 & 1.29 \% \\ \text { Chu et al [24] } & \text { Chinese population } & 2003 & 0.07 \% \\ \text { Saglam, Tuzum MS [23] } & \text { Turkish population } & 2003 & 0.3 \% \\ \text { Present study } & \text { Central Indian } & 2017 & 0.37 \%\end{array}$

Table V. Showing the prevalence of transmigration in different studies.

\begin{tabular}{|c|c|c|c|c|}
\hline Study & Population & Incidence in Maxilla & Incidence in Mandible & Year \\
\hline Sharma G, Nagpal A [25] & Indian population & $0.16 \%$ & $0.5 \%$ & 2014 \\
\hline Aktan et al [10] & Turkish subpopulation & $0.14 \%$ & 0.34 & 2010 \\
\hline B Kamiloglu and U Kelahmet [9] & Cypriote population & $0.44 \%$ & --- & 2014 \\
\hline Mupparapu [20] & --- & & 0.004 & 2002 \\
\hline Kumar et al [27] & & $0.46 \%$ & ----- & 2012 \\
\hline Present study & Central Indian population & 0 & $0.12 \%$ & 2017 \\
\hline
\end{tabular}




\section{Discussion}

In the present study the prevalence of impacted canines among the central Indian population was estimated to be $1.38 \%$. The prevalence of impacted maxillary canine was $0.94 \%$, which is lower than the study by Chu et al. [24] where they have found the prevalence of $2.1 \%$ in Caucasian and Chinese populations.

The prevalence of impacted mandibular canine in this study was found to be $0.37 \%$, which is higher than the study done by Rohrer A [15] where they have found the ratio of maxillary and mandibular impacted canine 20:1 ratio $(2.06 \%$ and $(0.1 \%)$, Grover and Lorton [27] reported $0.22 \%$, Chu et al (24) reported $0.07 \%$ among 7486 patients. In other studies by Aydin et al. [22] among Turkish population, the incidence reported was higher than the present study $0.44 \%$ which was studied among 4500 patients.

According to Takahama and Aiyama [28] the unilateral impaction was the most common finding, and according to Harzer [29] the side mostly affected was the left one. Other studies had different views, the higher incidence side being the right side [30,31]. In our study the most common impaction found was the unilateral canine impaction, which was observed in 14 subjects and the most common side affected was the right side in both genders, similar to the studies by Takahama and Aiyama [28], while Bass [32] found that the bilateral impaction was the most common finding. But in our study only 8 (eight) subjects out of 22 (twenty two) were found with bilateral canine impaction.

When it comes to the distribution of the prevalence of impacted canine according to the gender then the majority of studies found the higher prevalence to be among the females $[12,13]$. But equal occurrence of impacted canine in both the genders was reported by some studies [34,35]. In the present study we have also found almost equal prevalence among male and female subjects.

The tooth transposition occurs most frequently on the left side then the right side, in the maxillary arch, unilateral then bilateral and in females. Various studies finding the most common transposition occurrence to be between the canine and first premolar [36,37] and less frequent with the lateral incisor [36]. In this study one complete transposition and two incomplete canine transpositions were observed. The complete canine transposition occurred between the canine and the lateral incisor and primary canine was also retained. In the other two cases no retained deciduous canine and the lateral incisor was also in normal shape. The prevalence found was $0.18 \%$, the side involved in all three cases was the right side. This study does not agree with other studies which are in favor of left side to be the most common affected side by canine transposition.

The present study found the prevalence of canine transmigration in the mandibular arch $0.12 \%$ and in the maxillary arch none. This study result shows less incidence compared to the study done by Sharma G, Nagpal A [26], where they did the study among 3000 panoramic radiographs of north Indian population. The study by Aktan et al. [10] among Turkish subpopulation also shows a higher prevalence of $0.34 \%$ among 5000 subjects.

\section{Clinical implication}

The canine teeth are among the most important teeth in the oral cavity as they contribute to theaesthetic smile, canine guidance etc.

Knowledge of canine anomalies is necessary for the orthodontist to diagnose these anomalies at an early age in order to treat efficiently.

As the prevalence of canine impaction varies from one population to another population, it is of paramount importance that there should be data from all population groups.

\section{Conclusion}

There is no gender difference in canine impaction.

In the present study, the incidence of total impacted (mandibular and maxillary) canines was $1.38 \%$. The maxillary canine impaction $(0.93 \%)$ was more frequent than mandibular canine $(0.37 \%)$

The prevalence of canine agenesis was minimum $0.06 \%$ and the most common was ectopic canine $5.5 \%$.

\section{References}

1. Aslan BI, Üçüncü N. Clinical Consideration and Management of Impacted Maxillary Canine Teeth. In: Emerging Trends in Oral Health Sciences and Dentistry, InTechOpen 2015.

2. Lindauer SJ, Rubenstein LK, Hang WM, Andersen WC, Isaacson RJ. Canine impaction identified early with panoramic radiographs. J Am Dent Assoc. 1992;123:91-92, 95-97.

3. Nikiforuk G. Ectopic Eruption: Discussion and clinical report. J Ont Dent Assoc. 1948;25:243-246.

4. Pindborg JJ. Pathology of the dental hard tissues. Philadelphia: Sauders; 1970.

5. Thoma KH, Goldman HM. Oral pathology, ed. 5, St. Louis, CV Mosby Co. 1960, p 373.

6. Shapira Y, Kuftinec MM. Maxillary tooth transpositions: characteristic features and accompanying dental anomalies. Am J Orthod Dentofacial Orthop. 2001;119:127-134.

7. Tarsitano JJ, Wooten JW, Burditt JT. Transmigration of nonerupted mandibular canines: report of cases. J Am Dent Assoc. 1971;82:1395-1397.

8. Javid B. Transmigration of impacted mandibular cuspids. Int J Oral Surg. 985;14:547-549.

9. Pippi R, Kaitsas R. Mandibular canine transmigration: aethiopathogenetic aspects and six new reported cases. Oral Surgery. 2008;1:78-83.

10. Kamiloglu B, Kelahmet U. Prevalence of impacted and transmigrated canine teeth in a Cypriote orthodontic population in the Northern Cyprus area. BMC Res Notes. 2014;7:346.

11. Aktan AM, Kara S, Akgünlü F, Malkoç S. The incidence of canine transmigration and tooth impaction in a Turkish subpopulation. Eur J Orthod. 2010;32:575-581.

12. Gündüz K, Çelenk P. The incidence of impacted transmigrant canines: a retrospective study. Oral Radiology. 2010;26:77-81.

13. Dachi SF, Howell FV. A survey of 3,874 routine full-month radiographs: II. A study of impacted teeth. Oral Surg Oral Med 
Oral Pathol. 1961;14:1165-1169.

14. Thilander B, Myrberg N. The prevalence of malocclusion in Swedish schoolchildren. Scand J Dent Res. 1973;81:12-21.

15. Röhrer A. Displaced and impacted canines A radiographic research. International Journal of Orthodontia, Oral Surgery and Radiography. 1929;15:1003-1020.

16. Yavuz MS, Aras MH, Büyükkurt MC, Tozoglu S. Impacted mandibular canines. J Contemp Dent Pract. 2007;8:78-85.

17. Stivaros N, Mandall NA. Radiographic factors affecting the management of impacted upper permanent canines. J Orthod. 2000;27:169-173.

18. Power SM, Short MB. An investigation into the response of palatally displaced canines to the removal of deciduous canines and an assessment of factors contributing to favourable eruption. Br J Orthod. 1993;20:215-223.

19. Mupparapu M. Patterns of intra-osseous transmigration and ectopic eruption of mandibular canines: review of literature and report of nine additional cases. Dentomaxillofac Radiol. 2002;31:355-360.

20. Arandi N, Rabi T, Mustafa S. The Prevalence of Impacted Maxillary Canines in a Palestinian Population: A Retrospective Study. Open Journal of Stomatology. 2017;7:283.

21. Sajnani AK, King NM. Prevalence and characteristics of impacted maxillary canines in Southern Chinese children and adolescents. J Investig Clin Dent. 2014;5:38-44.

22. Aydin U, Yilmaz HH, Yildirim D. Incidence of canine impaction and transmigration in a patient population. Dentomaxillofac Radiol. 2004;33:164-169.

23. Sağlam AA, Tüzüm MS. Clinical and radiologic investigation of the incidence, complications, and suitable removal times for fully impacted teeth in the Turkish population. Quintessence Int. 2003;34:53-59.

24. Chu FC, Li TK, Lui VK, Newsome PR, Chow RL, Cheung LK. Prevalence of impacted teeth and associated pathologies--a radiographic study of the Hong Kong Chinese population. Hong
Kong Med J. 2003;9:158-63.

25. Sharma G, Nagpal A. A Study of Transmigrated Canine in an Indian Population. Int Sch Res Notices. 2014;2014:756516.

26. Kumar S, Jayaswal P, Pentapati KC, Valiathan A, Kotak N. Investigation of the transmigrated canine in an orthodontic patient population. J Orthod. 2012;39:89-94.

27. Grover PS, Lorton L. The incidence of unerupted permanent teeth and related clinical cases. Oral Surg Oral Med Oral Pathol. 1985;59:420-425.

28. Takahama Y, Aiyama Y. Maxillary canine impaction as a possible microform of cleft lip and palate. Eur J Orthod. 1982;4:275-277.

29. Harzer W. Retention von Z€ahnen: € Atiologie, Diagnostik and Therapie. In: Diedrich P, ed. Praxis der Zahnheilkunde. 12.M $€$ unchen-Jena: Urban and Fischer, 2002: pp 75-99.

30. Stahl F, Grabowski R. Maxillary canine displacement and genetically determined predisposition to disturbed development of the dentition. J Orofac Orthop. 2003;64:167-177.

31. Sacerdoti R, Baccetti T. Dentoskeletal features associated with unilateral or bilateral palatal displacement of maxillary canines. Angle Orthod. 2004;74:725-732.

32. Bass TB. Observations on the misplaced upper canine tooth. Dent Pract Dent Rec. 1967;18:25-33.

33. Becker A, Smith P, Behar R. The incidence of anomalous maxillary lateral incisors in relation to palatally-displaced cuspids. Angle Orthod. 1981;51:24-29.

34. Brin I, Becker A, Shalhav M. Position of the maxillary permanent canine in relation to anomalous or missing lateral incisors: a population study. Eur J Orthod. 1986;8:12-16.

35. Leifert S, Jonas IE. Dental anomalies as a microsymptom of palatal canine displacement. J Orofac Orthop. 2003;64:108-120.

36. Joshi MR, Bhatt NA. Canine transposition. Oral Surg Oral Med Oral Pathol. 1971;31:49-54.

37. Shapira Y. Transposition of canines. J Am Dent Assoc. 1980;100:710-712. 